\title{
Sapling transplanter : An effective tool for drudgery mitigation of women in vegetable production system
}

\author{
RITU GUPTA AND ANJULY SHARMA
}

Received: 26.07.2017; Revised: 08.11.2017; Accepted: 23.11.2017

See end of the paper for authors' affiliations RITU GUPTA

Department of Family Resource

Management, College of Home Science,

Punjab Agricultural University,

LUDHIANA (PUNJAB) INDIA

Email : rgupta@pau.edu
ABSTRACT : This study was conducted with an aim to assess the drudgery faced by women while doing transplanting in conventional way and compare it to the improved method using hand-operated sapling transplanter along with the sapling holding basket. For the field experiments, thirty female subjects were selected in the age group of 25- 45 years. The drudgery was assessed in terms of postural load using survey tool RULA and physiological stresses were measured in both the transplanting methods. The results revealed that with conventional method respondents performed this activity in standing-cum-forward bending posture, with shoulder, head, neck and hip flexion whereas with the hand-operated sapling transplanter the activity is performed in standing posture with slight bending of the neck. Mean value of working heart rate was assessed to be 109.4 beats/ min. in conventional transplanting and 97.5 beats/ min with sapling transplanter. Similarly, values of Total Cardiac Cost Work (1065.73 beats), Physiological Cost of Work (35.4 beats/ min.), energy expenditure rate $(10.20 \mathrm{~kJ} / \mathrm{min})$ in conventional transplanting of vegetables were reduced to 797.7 beats, 22 beats $/ \mathrm{min}$ and $8.62 \mathrm{~kJ} / \mathrm{min}$, respectively with the use of sapling transplanter. The results of the body map technique for pain indicator revealed that severe pain was felt in lower back by $66.7 \%$ respondents, upper back (46.7\% respondents), fingers and feet (43\%), whereas with the use of hand-operated sapling transplanter the intensity of pain was reduced to a great extent in majority of respondents. So, sapling transplanter along with the sapling basket proved to reduce the drudgery of farm workers.

KEY WORDS: Drudgery, Cardiac cost of work, Physiological cost of work, Postural stress, Musculoskeletal discomforts

- HOW TO CITE THIS PAPER : Gupta, Ritu and Sharma, Anjuly (2017). Sapling transplanter : An effective tool for drudgery mitigation of women in vegetable production system. Asian J. Home Sci., 12 (2) : 609-613, DOI: 10.15740/HAS/AJHS/12.2/609-613. 